\title{
CIHR Canadian HIV Trials Network Co-Infection and Concurrent Diseases Core: Updated Canadian guidelines for the treatment of hepatitis $\mathrm{C}$ infection in HIV-hepatitis $C$ coinfected adults
}

\author{
Mark Hull MD FRCPC ${ }^{1}$, Stephen Shafran MD FRCPC ${ }^{2}$, Alice Tseng BScPhm PharmD FCSHP3, \\ Pierre Giguère BPharm MSC ${ }^{4}$, Marina B Klein MD FRCPC ${ }^{5}$, Curtis Cooper MD FRCPC ${ }^{6}$; on behalf of The CIHR \\ Canadian HIV Trials Network HIV/Hepatitis C Management and Treatment Guidelines Working Group
}

M Hull, S Shafran, A Tseng, et al. CIHR Canadian HIV Trials Network Coinfection and Concurrent Diseases Core: Updated Canadian adult guidelines for the treatment of hepatitis $\mathrm{C}$ infection in HIV-hepatitis C coinfected patients. Can J Infect Dis Med Microbiol 2014;25(6):311-320.

BACKGROUND: Hepatitis C virus (HCV) coinfection occurs in $20 \%$ to $30 \%$ of Canadians living with HIV and is responsible for a heavy burden of morbidity and mortality. Management of HIV-HCV coinfection is more complex due to the accelerated progression of liver disease, the timing and nature of antiretroviral and HCV therapy, mental health and addictions management, socioeconomic obstacles and drug-drug interactions between new HCV direct-acting antiviral therapies and antiretroviral regimens.

OBJECTIVE: To update national standards for the management of HCV-HIV coinfected adults in the Canadian context.

METHODS: A standing working group with specific clinical expertise in HIV-HCV coinfection was convened by The Canadian Institute of Health Research HIV Trials Network to review recently published data regarding HCV antiviral treatments and to update the Canadian HIV-HCV coinfection guidelines.

RESULTS: Recent data suggest that the gap in sustained virological response rates between HCV monoinfection and HIV-HCV coinfection has been eliminated with newer HCV antiviral regimens. All HIV-HCV coinfected individuals should be assessed for HCV therapy. First-line treatment for genotypes 1 through 6 includes pegylated interferon and weight-based ribavirin dosing plus the nucleotide sofosbuvir for 12 weeks. Sofosbuvir in combination with the protease inhibitor simeprevir is another first-line consideration for genotype 1 infection. Sofosbuvir with ribavirin for 12 weeks (genotype 2) and 24 weeks (genotype 3 ) is also recommended as first-line treatment. DISCUSSION: Recommendations may not supersede individual clinical judgement.

Key Words: Antivirals; Coinfection; HCV; HIV; Treatment; Updated guidelines
Le domaine des co-infections et des maladies concomitantes du Réseau canadien pour les essais VIH des IRSC : mise à jour des lignes directrices canadiennes pour le traitement de l'infection par l'hépatite $\mathrm{C}$ chez des adultes co-infectés par le VIH

HISTORIQUE : De $20 \%$ à $30 \%$ des Canadiens qui vivent avec le VIH sont co-infectés par le virus de l'hépatite C (VHC), lequel est responsable d'une morbidité et d'une mortalité importantes. La prise en charge du VIH et du VHC est plus complexe en raison de l'évolution accélérée de la maladie hépatique, du choix et des critères d'initiation de la thérapie antirétrovirale et du traitement anti-VHC, de la prise en charge de la santé mentale et des toxicomanies, des obstacles socioéconomiques et des interactions entre les nouvelles thérapies antivirales à action directe du VHC et les antirétroviraux. OBJECTIF : Mettre à jour les normes nationales pour la prise en charge des adultes co-infectés par le VHC et le VIH dans le contexte canadien. MÉTHODOLOGIE : Le Réseau canadien pour les essais VIH des Instituts de recherche en santé du Canada a réuni un groupe d'experts possédant des compétences cliniques en co-infection par le VIH et le VHC pour réviser les publications récentes sur les traitements antiviraux contre le $\mathrm{VHC}$ et mettre à jour les lignes directrices canadiennes sur la co-infection du VIH et du VHC.

RÉSULTATS : Selon de récentes données, les nouvelles posologies antivirales ont éliminé la disparité entre le taux de réponse virologique soutenue de la mono-infection par le VIH et celui de la co-infection par le VIH et le VHC. Toutes les personnes co-infectées par le VIH et le VHC devraient subir une évaluation en vue de recevoir un traitement du VHC. Le traitement de première ligne du VHC des génotypes 1 à 6 inclut un régime composé d'interféron pégylé et de ribavirine dosée en fonction du poids, associé au sofosbuvir, un analogue des nucléotides, pendant 12 semaines. Le sofosbuvir combiné au siméprévir, un inhibiteur de la protéase, peut également constituer un traitement de première ligne pour l'infection par le génotype 1. Le sofosbuvir associé à de la ribavirine pendant 12 semaines (génotype 2) et 24 semaines (génotype 3) est également recommandé en première ligne.

EXPOSÉ : Les recommandations ne se substituent pas nécessairement au jugement clinique personnel.

publication of new information regarding dosing and duration of currently available agents for $\mathrm{HCV}$ therapy, two new $\mathrm{HCV}$ direct-acting antiviral agents (DAAs) have been licensed for use in Canada and the United States. The availability of these agents (sofosbuvir and
Since the publication of the Canadian guidelines for the manage$\checkmark$ ment and treatment of HIV-hepatitis $\mathrm{C}$ virus (HCV) coinfection in December 2013 (1), there have been substantial developments in the field of HCV therapeutic management. In addition to the
${ }^{1}$ University of British Columbia, British Columbia Centre for Excellence in HIV/AIDS, Vancouver, British Columbia; ${ }^{2}$ University of Alberta,
Edmonton, Alberta; ${ }^{3}$ Toronto General Hospital, Toronto; ${ }^{4}$ The Ottawa Hospital, Ottawa, Ontario; ${ }^{5}$ McGill University, Montreal, Quebec;

${ }^{6}$ University of Ottawa, Ottawa, Ontario

Correspondence and reprints: Dr Curtis Cooper, The Ottawa Hospital Division of Infectious Diseases, G12-501 Smyth Road, Ottawa,

Ontario K1H 8L6. Telephone 613-737-8924, fax 613-737-8164, e-mail ccooper@toh.on.ca 
TABLE 1

Virological response definitions while on hepatitis $C$ virus (HCV) therapy

\begin{tabular}{|c|c|c|c|}
\hline Definition & Time point & HCV RNA level & Comment \\
\hline RVR & Week 4 & Undetectable & High positive predictive value for SVR \\
\hline EVR & Week 12 & $\begin{array}{l}\text { Undetectable: Complete EVR } \\
\text { Detectable: Partial EVR }>2 \log _{10} \text { drop from baseline }\end{array}$ & $\begin{array}{l}\text { Lack of EVR has very high (>98\%) negative } \\
\text { predictive value for SVR }\end{array}$ \\
\hline
\end{tabular}

eRVR Week 4,12

Detectable: Null responder $<2 \log _{10}$ drop from baseline

Undetectable

High positive predictive value for SVR with telaprevir- and simeprevir-based triple therapy

Partial response Week 12+

EOT respons

Treatment completion (number of weeks, varies by regimen)

Relapser

Any time after EOT (usually checked 12 or 24 weeks after EOT)

SVR12 Week 60

SVR24

Week 72
Partial EVR at week 12 with no subsequent negative HCV RNA test

Undetectable

Undetectable at EOT, detectable after EOT

Undetectable

Undetectable
Treatment failure (pEVR + week $24 \mathrm{HCV}$ RNA

detectable, has $100 \%$ NPV for SVR)

Treatment failure (relapse $>12$ weeks after EOT suggests possibility of reinfection; viral sequencing should be considered)

Predicts SVR24 in monoinfected patients

Treatment success

EOT End of treatment; eRVR Extended rapid virological response; EVR Early virological response; NPV Negative predictive value; $p E V R$ Partial EVR; RVR Rapid virological response; SVR Sustained virological response; SVR12 SVR after 12 weeks of follow-up; SVR24 SVR after 24 weeks of follow-up

simeprevir) has required revised recommendations for therapy in HCV monoinfected individuals (2). Furthermore, it is anticipated that several interferon-free, oral combination DAA regimens will be approved by Health Canada within a year (3-5). In the present article, we review current protocols for the treatment of $\mathrm{HCV}$ in the setting of HIV coinfection and make recommendations for the use of the newer, currently available HCV DAAs. These guidelines will continue to be updated on a regular basis as new agents become available for use.

\section{CURRENT HCV THERAPY IN GENOTYPE 1 COINFECTED PATIENTS}

The standard of care for genotype $1 \mathrm{HCV}$-infected individuals since the latter part of 2011 comprises triple therapy with pegylated interferon, ribavirin and a HCV protease inhibitor (boceprevir or telaprevir). Published phase III studies investigating both boceprevir and telaprevir in HCV-monoinfected populations demonstrate markedly improved sustained virological response (SVR) rates compared with dual peginterferon plus ribavirin therapy in treatment-naive, previous relapser, previous partial responder and previous null responder populations (6-9).

Results from two phase II randomized comparative studies indicate markedly improved SVR outcomes with these triple-therapy regimens for HCV genotype 1 treatment-naive patients coinfected with HIV $(10,11)$. SVR rates achieved in these studies now approximate those observed in monoinfected patients (63\% to $74 \%$ ), a significant improvement over the rates observed in pegylated interferon/ribavirin trials (12).

\section{Telaprevir-based therapy in coinfection}

A randomized, double-blinded clinical trial compared pegylated interferon $\alpha-2 \mathrm{a}$ and ribavirin with or without telaprevir in HIV-seropositive, HCV genotype 1 -infected patients not receiving antiretroviral therapy (ART) with CD4 counts $>500$ cells $/ \mu L(n=13$, Part A) and in patients receiving suppressive ART ( $\mathrm{n}=24$, Part B) (10). Overall, $74 \%$ of patients receiving telaprevir achieved an SVR, compared with $45 \%$ of those receiving pegylated interferon and ribavirin. Relapse rates were $3 \%$ for patients receiving telaprevir versus $15 \%$ in patients receiving pegylated interferon and ribavirin. SVR rates were similar between patients taking ART and those not taking ART. Serious adverse events were observed in 5\% of patients receiving 48 weeks of fixedduration pegylated interferon $\alpha-2 \mathrm{a}$ and ribavirin (the majority received fixed $800 \mathrm{mg}$ ribavirin dosing with a few subjects receiving weightbased dosing). Patients were dosed with either 12 weeks of telaprevir $750 \mathrm{mg}$ every $8 \mathrm{~h}$, or $1125 \mathrm{mg}$ every $8 \mathrm{~h}$ for patients on efavirenz due to anticipated drug-drug interactions.

Interim analyses from three additional studies now support the use of telaprevir in treatment-experienced coinfected patients. These trials demonstrate comparable outcomes with a twice-daily dose of $1125 \mathrm{mg}$ telaprevir in coinfected patients, which has previously been shown to be noninferior to standard dosing (every $8 \mathrm{~h}$ ) in monoinfected individuals (13). In addition, they provide supportive evidence for the use of response-guided therapy in HCV treatment-naive patients and those with previous relapse. Finally, these new data provide evidence for the use of telaprevir in treatment-experienced patients, a population not included in the original coinfection trial.

In the UNITE phase III open-label study, 182 participants received telaprevir-based therapy (dosed twice daily); treatment-naive and previous relapsers received response-guided therapy if rapid virological response (RVR; refer to Table 1 for definitions) on treatment was demonstrated, while patients without RVR as well as previous partial and null responding patients were offered a fixed 48-week course of therapy (14). The SVR at 12 weeks of follow-up (SVR12) rates obtained were similar to those observed previously, with $67 \%$ of naive individuals, $68 \%$ of previous relapsers and $60 \%$ of partial responders achieving SVR. SVR rates were lower in previous null responders, with only $39 \%$ achieving SVR12. Overall, 97\% experienced an adverse event during therapy, $13 \%$ of which were serious adverse events. In the INSIGHT open-label trial, 164 participants (98 of whom were treatmentexperienced, including 51 previous null-responders) received standard telaprevir-based therapy dosed three times daily (every $8 \mathrm{~h}$ ) in a similar response-guided algorithm (15). Complete early virological response rates were high, with $80 \%$ of naive individuals, $83 \%$ of those with previous partial response and $57 \%$ of null responders achieving undetectable HCV RNA levels at week 12 of treatment (15).

In ANRS HC-26 ( $\mathrm{n}=69,39 \%$ relapsers, 31\% previous partial responders/breakthrough and 30\% noncirrhotic null responders) participants received a four-week lead-in of pegylated interferon and weight-based ribavirin, 12 weeks of triple therapy with the addition of telaprevir, with an additional course of pegylated interferon and ribavirin for a total of 48 or 72 weeks in a response-guided manner dependent on results of the week 8 (week 4 triple-therapy outcome) (16). Patients were included if they had stable CD4 cell counts $>200$ cells $/ \mu \mathrm{L}(\mathrm{CD} 4 \%>15 \%)$ with suppressed HIV viral load on efavirenz, atazanavir/ritonavir or raltegravir-based regimens. The METAVIR score was F3 in 16\%, and 23\% were cirrhotic (F4). SVR at 24 weeks of follow-up (SVR24 response; Table 1) was achieved in $80 \%$ of individuals and did not appear to be influenced by the fibrosis stage (F1 to F2 83\%, F3 to F4 78\%), or previous response type (with EOT achieved by those with previous relapse $74 \%$, previous breakthrough $83 \%$, partial response $100 \%$ and previous null response $71 \%$ ), although sample size for these subgroups was small. Grade 4 adverse events occurred in $22 \%$ of cases, including anemia (10\%) and 
infections (3\%). Dose reduction of pegylated interferon or ribavirin was required in $22 \%$ and $43 \%$, respectively. Sixty-five percent of study participants were administered erythopoietin and $23 \%$ required blood transfusion during the extended course of therapy (17).

\section{Boceprevir-based therapy in coinfection}

Boceprevir was evaluated in 98 coinfected patients in a placebocontrolled randomized trial (11). All patients were on ART with stable HIV suppression. Antiretroviral regimens allowed in this study consisted of a ritonavir-boosted protease inhibitor, raltegravir or maraviroc in conjunction with two nucleoside inhibitors other than zidovudine, stavudine or didanosine. Most participants were receiving atazanavir, lopinavir or darunavir-based regimens. Non-nucleoside reverse transcriptase inhibitor-based regimens were not allowed in this protocol. Only five of 98 participants were cirrhotic. All participants received 48 weeks of therapy consisting of a standard four week lead-in phase with pegylated interferon $\alpha-2 b$ and weight-based ribavirin, followed by a fixed duration of 44 weeks of boceprevir $800 \mathrm{mg}$ every $8 \mathrm{~h}$ or placebo. Overall, an SVR24 was achieved in 63\% of triple-therapy recipients ( $n=64$ ) versus $29 \%$ of pegylated interferon $\alpha-2 b$ and ribavirin treated study participants $(n=34)(11)$. Adverse events were common in those receiving boceprevir (41\% versus 26\%). Despite the successful use of HIV protease inhibitors in this trial, subsequent pharmacokinetic studies have suggested potential for significant interactions (drug interactions with HCV DAAs are summarized in Table 2).

In ANRS HC-27, treatment-experienced patients $(n=64)$ received a standard lead-in phase followed by 44 weeks of triple therapy with boceprevir (18). Individuals with cirrhosis and previous null response to pegylated interferon and ribavirin were excluded. Those without a week 8 RVR completed an additional 24 weeks (total 72 weeks) of pegylated interferon with ribavirin. The overall SVR12 rate was 53\%, with SVR rates of $90 \%$ in previous relapsers, $61 \%$ in those with partial response and $24 \%$ in null responders. In this trial, there was an apparent difference in outcome based on underlying ART regimen, with a $41 \%$ SVR rate in patients receiving atazanavir/ritonavir compared with $70 \%$ in those receiving raltegravir (19).

\section{Conclusion}

These results demonstrate that response rates for treatment-naive patients are improved with pegylated interferon, ribavirin and an HCV protease inhibitor compared with SVR rates achieved with pegylated interferon/ribavirin alone. SVR rates approximate those observed in monoinfection, with reduced SVR rates observed in those with more advanced disease. In addition, the encouraging interim findings suggest that treatment-experienced coinfected patients will achieve SVR outcomes similar to those observed in monoinfected patients, with the highest SVR rates in previous relapsers (higher than treatment-naive patients), intermediate SVR rates in previous partial responders and the lowest SVR rates in previous null responders. Adverse events, particularly anemia, were common but similar in characteristic and rate to that of HCV monoinfected treatment recipients. These results highlight the need for improved therapeutic options for all HCV-infected individuals with advanced disease or previous treatment failure.

\section{NEXT-GENERATION DAAs: SIMEPREVIR AND SOFOSBUVIR}

Two new DAAs have recently been approved in Canada and the United States for the treatment of $\mathrm{HCV}$; the NS3/4A protease inhibitor simeprevir, and the novel uridine nucleotide NS5B RNA-dependent RNA polymerase inhibitor sofosbuvir. These agents offer marked improvement over current therapies because they exhibit muchimproved side effect profiles, fewer drug-drug interactions, reduced pill burden and, in the case of sofosbuvir, offer pan-genotypic coverage with the potential for interferon-free based therapy for all genotypes. As such, they have superseded the use of both telaprevir and boceprevir in current treatment recommendations in the United States (20).

\section{Simeprevir}

Simeprevir is a second-wave NS3/4A protease inhibitor that offers a number of advantages over boceprevir and telaprevir. The recommended dose in adults with genotype 1 infection is $150 \mathrm{mg}$ once daily with food. Food delays the absorption of simeprevir, increasing the time to reach maximum plasma concentration by $1 \mathrm{~h}$ to $1.5 \mathrm{~h}$, and increases the exposure of simeprevir by approximately $60 \%$. Simeprevir is available as a $150 \mathrm{mg}$ capsule, allowing for a significant reduction in pill burden compared with its predecessors in this class. Simeprevir is a substrate of cytochrome P450 (CYP) 3A4, and a mild inhibitor of intestinal (but not hepatic) CYP3A4, 1A2, P-glycoprotein (P-gp) and organic anion transporting polypeptides $1 \mathrm{~B} 1$ (20). Simeprevir has no clinically relevant effects on CYP2C9, 2C19 and 2D6 (20). Due to these characteristics, simeprevir is primarily the subject (rather than a perpetrator) of pharmacokinetic drugdrug interactions. Coadministration of simeprevir with moderate to strong inducers or inhibitors of CYP3A4 is not recommended due to the potential for significant alterations in simeprevir plasma concentrations. Clinically, this restricts antiretroviral choices for HIV-HCV coinfected patients because regimens including ritonavir or cobicistat as a booster, or the non-nucleoside reverse transcriptase inhibitors efavirenz, etravirine and nevirapine, should not be used (Tables 2 and 3). Similarly, other inducing/inhibiting agents, such as anticonvulsants, rifamycins, dexamethasone, azole antifungals and macrolides, should be avoided with simeprevir. In the transplant population, simeprevir may be preferred over telaprevir or boceprevir due to the absence of drug interactions with tacrolimus and cyclosporine (21).

Use of simeprevir in conjunction with pegylated interferon and ribavirin has been shown to achieve similar improvement in SVR rates in phase II studies, in both naive and experienced HCV monoinfected patients $(22,23)$. Simeprevir used in a response-guided protocol has been assessed in three large phase III clinical trials in HCV monoinfected treatment-naive individuals (QUEST-1, QUEST-2) and previous relapsers (PROMISE) (24-26). In these trials, simeprevir $150 \mathrm{mg}$ daily for the initial 12 weeks of triple therapy with response-guided pegylated interferon/ribavirin for 24 or 48 weeks resulted in SVR12 rates of $80 \%$ to $81 \%$ in naive individuals compared with $50 \%$ for those receiving pegylated interferon/ribavirin alone. Overall, among naive individuals, the majority (80\% in QUEST-1 and 91\% in QUEST-2) met criteria for response-guided therapy (ie, 24 weeks total), based on a HCV polymerase chain reaction test $<25 \mathrm{IU} / \mathrm{mL}$ at week 4 with undetectable HCV RNA at week 12. Response rates among those who met these criteria were high at $86 \%$ to $91 \%$. Previous relapsers showed similar benefit, with $79 \%$ of those treated with simeprevir achieving SVR12 compared with $37 \%$ in the control arm (26). The majority of individuals $(92.7 \%)$ were eligible for response-guided therapy and, of these, $83 \%$ achieved SVR12.

Data regarding treatment-experienced $\mathrm{HCV}$ monoinfected patients are derived from the phase II ASPIRE trial (23), in which individuals who received 48 weeks of pegylated interferon and ribavirin had SVR2 4 rates of $88 \%$ in previous relapsers, $86 \%$ in previous nonresponders and $58 \%$ in previous null responders. Recently, the results of the phase III ATTAIN trial, the only head-to-head randomized trial of two HCV protease inhibitors, showed comparable SVR rates with 12 weeks of simeprevir versus 12 weeks of telaprevir, each given with 48 weeks of pegylated interferon alfa-2a for 48 weeks in patients with HCV genotype 1 infection who were partial or null responders to previous dual therapy with peginterferon plus ribavirin (27). Specifically, SVR12 rates were $70 \%$ and $44 \%$ in partial and null responders, respectively, treated with simeprevir versus $69 \%$ and $46 \%$, respectively, in those treated with telaprevir. There was a lower incidence of anemia and fewer discontinuations for adverse events in simeprevir recipients.

The side effect profile for individuals receiving simeprevir was similar to those on pegylated interferon and ribavirin, with no significant additional toxicities identified. A naturally occurring HCV NS3 polymorphism - the Q80K mutation - was associated with reduced 
TABLE 2

Drug-drug interactions between antiretroviral agents and direct-acting antivirals for hepatitis $\mathrm{C}$

\begin{tabular}{cccc}
\hline & Boceprevir & Telaprevir & Simeprevir \\
\hline Dose & $800 \mathrm{mg}$ every $8 \mathrm{~h}$ with food & $\begin{array}{c}1125 \mathrm{mg} \text { every } 12 \mathrm{~h} \text { with food } \\
\text { (not low fat) }\end{array}$ & $150 \mathrm{mg}$ daily with food
\end{tabular}

\section{Integrase inhibitors}

Dolutegravir No clinically significant changes in either drug. No dose adjustment required $(59,60)$

Elvitegravir/ Coadministration has not been cobicistat studied but could lead to reduced drug concentrations of both boceprevir and elvitegravir/ cobicistat

Raltegravir No clinically significant changes in either drug. No dose adjustment required (63)

Non-nucleoside reverse transcriptase inhibitors

Efavirenz

$44 \% \downarrow$ Cmin, $19 \% \downarrow$ AUC of
boceprevir. Avoid combination.
$(67,68)$

Etravirine

\section{$29 \% \downarrow$ Cmin, 23\% $\downarrow$ AUC of} etravirine. Use combination with caution, particularly if coadministering with other medications that may further decrease etravirine concentrations (71)

Rilpivirine $\quad \uparrow 39 \%$ AUC, $\uparrow 15 \%$ Cmax,$\uparrow 10 \%$ $\mathrm{Cmin}$ of rilpivirine, not considered to be clinically significant. No dose adjustment required (73)

\section{Protease inhibitors}

Atazanavir/ $\quad 49 \% \downarrow$ Ctrough, 35\% $\downarrow$ AUC of ritonavir atazanavir. Avoid combination $(68,74)$

Darunavir/ $59 \% \downarrow$ Ctrough, $44 \% \downarrow$ AUC of ritonavir darunavir and $32 \% \downarrow$ boceprevir. Avoid combination $(68,74)$

$40 \% \downarrow$ AUC and $42 \% \downarrow$ Cmin of darunavir, 35\% $\downarrow$ AUC and 32\% $\downarrow$ Cmin of telaprevir. Avoid combination $(70,75)$

\section{Cmin of rilpivirine, not} considered clinically significant. No dose adjustment required (72) required $(59,60)$

No clinically significant changes in either drug. No dose adjustment required $(61)$

No clinically significant changes in either drug. No dose adjustment required (64)

$47 \% \downarrow$ Cmin of telaprevir; $\uparrow$ telaprevir dose to $1125 \mathrm{mg}$ every 8 h with efavirenz $(69,70)$

No clinically significant changes in required $(72)$

$85 \% \uparrow \mathrm{Cmin}$ of atazanavir

Combination may be used (70)

$47 \% \downarrow$ AUC and $56 \% \downarrow$ Cmin of amprenavir, 32\% $\downarrow$ AUC and $30 \% \downarrow$ Cmin of telaprevir. Avoid combination $(70,75)$

Fosamprenavir/ Not recommended with ritonavirritonavir boosted protease inhibitors (68)

Lopinavir/ ritonavir $43 \% \downarrow$ Ctrough, 34\% $\downarrow$ AUC of lopinavir and $45 \% \downarrow$ boceprevir. Avoid combination $(68,74,76)$ lopinavir, 54\% $\downarrow$ AUC and 52\% $\downarrow$ Cmin of telaprevir. Avoid
$91 \% \downarrow \mathrm{Cmin}, 71 \% \downarrow$ AUC of simeprevir. Avoid combination. $(20,62)$

Coadministration has not been studied but no expected clinically significant drug interaction

\section{Not recommended with} cobicistat-boosted regimens due to risk of significantly increased simeprevir concentrations $(20,62)$

No clinically significant changes in either drug. No dose adjustment required (65)

\section{Not recommended with} decreased simeprevir concentrations (20)

$6 \% \uparrow$ AUC, $4 \% \downarrow$ Cmin of simeprevir and 12\% $\uparrow$ AUC 25\% $\uparrow$ Cmin of rilpivirine, not considered clinically significant. No dose adjustment required (65) etravirine due to risk of
$6 \% \uparrow \mathrm{AUC}$ and $14 \% \uparrow \mathrm{Cmin}$ of combination $(70,75,76)$

Coadministration has not been studied but no expected clinically significant drug interaction

Coadministration has not been studied but no expected clinically significant drug interaction

No clinically significant changes in either drug. No dose adjustment required $(20,66)$

$6 \% \downarrow$ AUC, $19 \% \downarrow$ Cmax of sofosbuvir, not considered clinically significant. No dose adjustment required $(20,66)$

Coadministration has not been studied but no expected clinically significant drug interaction

$6 \% \uparrow$ AUC, $5 \% \uparrow$ Cmax of rilpivirine, not considered clinically significant. No dose adjustment required $(20,66)$

Not recommended with ritonavir, boosted or unboosted HIV protease inhibitors due to risk of significantly increased simeprevir concentrations (20)

2.6-fold $\uparrow$ AUC, 1.79-fold $\uparrow \mathrm{Cmax}$, 4.58-fold $\uparrow$ Cmin of simeprevir and $18 \% \uparrow A \cup C, 31 \% \uparrow \mathrm{Cmin}$ of darunavir. Coadministration not recommended (20)

Not recommended with ritonavir, boosted or unboosted HIV protease inhibitors due to risk of significantly increased simeprevir concentrations $(20,62)$

Not recommended with ritonavir, boosted or unboosted HIV protease inhibitors due to risk of significantly increased simeprevir concentrations (20)
No expected clinically significant drug interaction

37\% $\uparrow$ AUC, $45 \% \uparrow$ Cmax of sofosbuvir, not considered clinically significant. No dose adjustment required $(20,66)$

Coadministration has not been studied but no expected clinically significant drug interaction

\section{Coadministration has not been} studied but no expected clinically significant drug interaction

No expected clinically significant drug interaction
Coadministration has not been studied but no expected clinically significant drug interaction
$233 \%$ and Ctrough $\uparrow 178 \%$ vs maraviroc 150 mg BID alone.

Reduce maraviroc dose to

150 mg BID when coadminis-

tering with boceprevir $(77,78)$
Maraviroc AUC $\uparrow 849 \%, \mathrm{Cmax} \uparrow$

$681 \%$ and Ctrough $\uparrow 917 \%$ vs maraviroc 150 mg BID alone. Reduce maraviroc dose to 150 mg BID when coadministering with telaprevir (77)

Key: $\square$ Avoid combination; $\square$ Caution/dose adjustment; $\square$ Combination OK. $\uparrow$ Increase; $\downarrow$ Decrease; AUC Area under the curve; BID Twice per day; CCR5 C-C chemokine receptor-5; Cmax Concentration maximum; Cmin Concentration minimum; Ctrough Concentration trough; vs Versus 
TABLE 3

Summary of antiretroviral regimen recommendations for patients who require concomitant HIV and hepatitis C treatment

\begin{tabular}{|c|c|c|c|}
\hline & Recommended & Alternative & NOT recommended \\
\hline Sofosbuvir 400 mg daily & $\begin{array}{l}\text { No restrictions on antiretroviral } \\
\text { choices }\end{array}$ & $\begin{array}{l}\text { No restrictions on antiretroviral } \\
\text { choices }\end{array}$ & \\
\hline $\begin{array}{l}\text { Simeprevir } 150 \text { mg daily with } \\
\text { food }\end{array}$ & $\begin{array}{l}\text { Dolutegravir-, raltegravir- or } \\
\text { rilpivirine-based regimens }\end{array}$ & & $\begin{array}{l}\text { Ritonavir- or cobicistat-boosted regimens; efavirenz, } \\
\text { etravirine, nevirapine }\end{array}$ \\
\hline $\begin{array}{l}\text { Telaprevir } 1125 \text { mg BID with } \\
\text { food (not low fat) }\end{array}$ & $\begin{array}{l}\text { Atazanavir/ritonavir-, dolutegravir-, } \\
\text { elvitegravir-, raltegravir- or } \\
\text { rilpivirine-based regimens }\end{array}$ & $\begin{array}{l}\text { Efavirenz (with increase in telaprevir } \\
\text { dose to } 1125 \mathrm{mg} \text { every } 8 \mathrm{~h} \text { ), } \\
\text { etravirine }\end{array}$ & $\begin{array}{l}\text { Other protease inhibitor-based regimens including } \\
\text { darunavir/ritonavir, fosamprenavir/ritonavir, } \\
\text { lopinavir/ritonavir }\end{array}$ \\
\hline $\begin{array}{l}\text { Boceprevir } 800 \mathrm{mg} \text { every } 8 \mathrm{~h} \\
\text { with food }\end{array}$ & $\begin{array}{l}\text { Dolutegravir-, raltegravir- or } \\
\text { rilpivirine-based regimens }\end{array}$ & & $\begin{array}{l}\text { Protease inhibitor-based regimens including } \\
\text { atazanavir/ritonavir, darunavir/ritonavir, lopinavir/ } \\
\text { ritonavir; other NNRTI-based regimens including } \\
\text { efavirenz, etravirine, nevirapine }\end{array}$ \\
\hline
\end{tabular}

BID Twice daily; NNRTI Non-nucleoside reverse transcriptase inhibitors

SVR rates in genotype 1a patients. This polymorphism occurs in approximately $45 \%$ of North Americans with genotype 1a (28) but only approximately $18 \%$ of Europeans (29). In the QUEST-1 study, those with this mutation had no better response rate with the addition of simeprevir compared with those in the pegylated interferon/ ribavirin arm (24). Screening at baseline for this mutation in genotype 1 a is recommended.

\section{Data in coinfected patients}

Simeprevir has been evaluated in treatment-naive and -experienced HIV coinfected patients (30). In the C212 open-label phase III study, 106 individuals received either response-guided therapy for naive/ relapsers $(n=64)$ or standard 12 weeks of triple therapy followed by 36 weeks of pegylated interferon/ribavirin in treatment-experienced patients or those with underlying cirrhosis. Due to potential drug interactions, ART regimens were limited to raltegravir, maraviroc or rilpivirine, with either tenofovir/emtricitabine or abacavir/lamivudine. Overall SVR 12 rates were achieved in $79 \%$ of naive individuals, $87 \%$ of previous relapsers, $70 \%$ of previous partial responders and $57 \%$ of null responders. Response rates were reduced in those with cirrhosis (64\%) versus noncirrhotics $(80 \%)$ and side effect profile was similar to what is expected with peginterferon plus ribavirin alone.

\section{Sofosbuvir}

Sofosbuvir is a nucleotide prodrug that undergoes intracellular metabolism to form the pharmacologically active uridine analogue triphosphate GS-461203, which is incorporated into HCV RNA by the NS5B polymerase and acts as a chain terminator. Sofosbuvir is available as a $400 \mathrm{mg}$ tablet. The approved dose in adults is $400 \mathrm{mg}$ once daily taken without regard to food. After oral administration, sofosbuvir is rapidly converted to the predominant circulating metabolite GS-331007. Sofosbuvir and GS-331007 do not inhibit any CYP450 isoenzymes or UGT1A1. Sofosbuvir is a P-gp substrate and breast cancer resistance protein substrate whereas GS-331007 is not. Sofosbuvir should not be coadministered with potent P-gp inducers such as rifampin or St John's wort (31). Significant interactions have not been demonstrated or are not expected between sofosbuvir and antiretrovirals.

Sofosbuvir has been widely evaluated in HCV monoinfected individuals. In the phase III NEUTRINO study, 291 genotype 1 -infected treatment-naive individuals received 12 weeks of triple therapy with sofosbuvir $400 \mathrm{mg}$ daily in conjunction with pegylated interferon and ribavirin (32). Overall SVR12 rates were achieved in $89 \%$ of individuals, with lower rates observed in those with cirrhosis than in those without ( $80 \%$ versus $92 \%$ ). Side effects appear to be driven predominantly by the receipt of pegylated interferon/ribavirin, although a control group for definitive comparison was not built into the study design. In addition, use of sofosbuvir with ribavirin alone has been evaluated for interferon-ineligible patients with genotype 1 infection. In a small $(n=60)$ phase II study, sofosbuvir with weight-based ribavirin for 24 weeks achieved an SVR24 rate of $68 \%$ in individuals deemed to be interferon-ineligible (33). A relatively high rate of relapse (54\%) was observed in those with more advanced disease. Other small trials (ELECTRON, QUANTUM trials) of this interferon-sparing strategy have found SVR rates ranging from $50 \%$ to $84 \%(34,35)$.

Limited data exist for treatment-experienced patients. However, given the response observed in individuals with characteristics that would normally be considered to be unfavourable for response to pegylated interferon and ribavirin, modelling conducted during the approval of sofosbuvir by the United States Food and Drug Administration (FDA) predicts an approximate $78 \%$ response in treatment-experienced patients (36).

\section{Genotypes 2 and $3 \mathrm{HCV}$ monoinfection}

Sofosbuvir has also been evaluated for use in genotypes 2 and 3 in an initial large noninferiority comparison to standard pegylated interferon/ribavirin (32). In the FISSION trial, 499 treatment-naive individuals were randomly assigned to 12 weeks of therapy with sofosbuvir/ ribavirin or 24 weeks of pegylated interferon/ribavirin. Individuals with genotype 2 infection had exceptional SVR rates of $97 \%$ with sofosbuvir/ ribavirin versus $76 \%$ with pegylated interferon/ribavirin, while those with genotype 3 achieved similar SVR rates to pegylated interferon/ribavirin (56\% versus 63\%). Cirrhosis markedly reduced SVR rates for genotype 3 individuals to approximately 30\% in both arms. Similar SVR rates were observed in the POSITRON trial in interferon-ineligible patients (37). In the phase III VALENCE study, improved SVR rates were observed in genotype 3 treatment-naive individuals who received 24 weeks of sofosbuvir/ribavirin with SVR rates $94 \%$, with the subgroup of cirrhotic patients achieving SVR of $90 \%(38)$.

Sofosbuvir has also been evaluated in treatment-experienced genotype 2 and 3 patients. In the FUSION trial, individuals were randomly assigned to receive 12 or 16 weeks of therapy with sofosbuvir and ribavirin. Those with genotype 2 achieved an SVR rate of $86 \%$ after 12 weeks and $94 \%$ after 16 weeks. SVR rates were much lower for genotype 3, with an SVR rate of 30\% in patients receiving 12 weeks versus $62 \%$ in those who received 16 weeks of therapy (37). In the VALENCE study, treatment-experienced genotype 2 patients experienced similar high rates of response (91\%) after 12 weeks of therapy of dual therapy. Treatment-experienced patients with genotype 3 treated with 24 weeks of sofosbuvir and ribavirin achieved an SVR of $87 \%$ in those without cirrhosis, and only $60 \%$ in those with cirrhosis (39). In the LONESTAR-2 phase II trial, the addition of pegylated interferon to a 12 week course of sofosbuvir/ribavirin resulted in SVR rates of $83 \%$ for genotype 3 , with or without cirrhosis (40).

Data in HIV-HCV coinfected patients

Sofosbuvir was evaluated in HIV coinfected patients in the phase II Study 1910 trial (41). In this open-label study, 23 coinfected treatmentnaive individuals received sofosbuvir $400 \mathrm{mg}$ daily in conjunction 
with pegylated interferon and weight-based ribavirin for 12 weeks. Individuals were predominantly genotype 1 -infected, with two individuals with genotype 3, and one individual each with genotype 2 and 4, respectively, were also enrolled. The ART regimens included efavirenz, rilpivirine, raltegravir and the boosted protease inhibitors atazanavir and darunavir. Overall, the SVR12 was 91\%. Side effects were predominantly those of pegylated interferon and ribavirin.

In the phase III PHOTON-1 study, three cohorts of coinfected patients (genotype 1 treatment-naive patients $n=114$, genotype 2 $(n=28)$ and $3(n=42)$ naive patients, and genotypes $2 / 3$ treatmentexperienced patients $(n=41)$ were enrolled to receive either 12 weeks or 24 weeks (genotype 1 and treatment-experienced patients) of sofosbuvir with ribavirin (42). Individuals could be on a wide range of ART regimens due to the lack of drug interactions, or naive to ART if baseline CD4 cell count was $>500$ cells $/ \mathrm{mm}^{3}$. The majority of those enrolled were on ART, receiving predominantly efavirenz-, atazanavir- or darunavir-based regimens. The SVR24 rate was $75 \%$ for genotype 1 participants, $88 \%$ for genotype 2 and $67 \%$ for genotype 3 patients. Among treatment-experienced patients, SVR 24 was attained by $92 \%$ of genotype 2 and $88 \%$ of genotype 3 individuals. Overall, the regimen was well tolerated, with more adverse events related to sofosbuvir/ribavirin observed in patients receiving a 24-week course of therapy.

\section{DAA COMBINATION REGIMENS OF CURRENTLY APPROVED AGENTS}

Proof-of-concept studies investigating interferon-free and ribavirin-sparing combinations of potent DAA agents have rapidly advanced the potential for simple, potent and well-tolerated therapies for HCV (4345). Further evaluation of combination DAA therapy has demonstrated potential therapy in patients with advanced disease, in previous null responders and as salvage therapy in patients previously nonresponsive to telaprevir and boceprevir-based therapy $(3,46,47)$. In the COSMOS study, HCV monoinfected, treatment-naive and previous null responders with HCV genotype 1 monoinfection received once-daily simeprevir and sofosbuvir, with or without ribavirin for either 12 or 24 weeks (46). In the first cohort of 80 null responders with METAVIR FO-F2 disease, SVR12 rates with dual therapy were high (92\% to $93 \%$ after 12 or 24 weeks of therapy) and the addition of ribavirin was not clearly associated with improvement in SVR rates (48). For the second cohort of 87 naive and null responders with F3-F4 disease, SVR12 rates were 93\% with 12 weeks of therapy and $96 \%$ with 24 weeks of therapy (49). The addition of ribavirin did not increase SVR rates but did result in some cases of anemia (4). On the basis of the COSMOS data, two phase III studies will evaluate eight versus 12 weeks of sofosbuvir plus simeprevir in noncirrhotic patients (OPTIMIST-1) and 12 weeks in cirrhotic patients (OPTIMIST-2) in HCV genotype 1 monoinfected treatment-naive patients (50). Ribavirin will not be included in the phase III studies. At present, no data exist for this combination in coinfected individuals.

\section{FUTURE DAA COMBINATIONS}

Interferon-free combination DAA regimens have been or soon will be approved by regulatory agencies, including Health Canada. We anticipate that the regimens mentioned below will rapidly be identified as first-line therapies for HCV. However, as HIV-HCV coinfectionspecific clinic trials evaluating these new regimens have yet to be published, they have not been included in this current iteration of the Canadian Institutes of Health Research Canadian HIV Trials Network HIV-HCV coinfection guidelines.

The combination of sofosbuvir with a NS5A replication inhibitor is particularly promising. This was first demonstrated in a phase II study with the NS5A inhibitor daclatasvir, with SVR rates of 98\% in genotype 1,92\% in genotype 2 and $89 \%$ in genotype 3 (51). Moreover, the combination of sofosbuvir plus daclatasvir resulted in SVRs in $100 \%$ of 41 patients who previously failed triple therapy with peginterferon, ribavirin and either telaprevir or boceprevir.

Very recently, three phase III trials investigating the fixed-dose combination of sofosbuvir with the NS5A inhibitor ledipasvir, with and without ribavirin for eight or 12 weeks in patients with HCV genotype 1 monoinfection demonstrated SVR rates of $93 \%$ to $99 \%$, including boceprevir- or telaprevir treatment experienced patients and those with cirrhosis $(4,52)$. The addition of ribavirin did not increase SVR rates. A New Drug Application for sofosbuvirledipasvir was filed with the US FDA on February 10, 2014 and received approval in the United States and Canada in October 2014 (53). The combination of sofosbuvir/ledipasvir for 12 weeks is currently under study in HIV-HCV coinfected patients in the ION-4 protocol.

The combination of three DAAs, specifically the NS3 protease inhibitor ABT-450 boosted by the CYP3A4 inhibitor ritonavir, the NS5A inhibitor ombitasvir and the NS5B non-nucleoside polymerase inhibitor dasabuvir, with ribavirin given for 12 weeks results in SVR rates of $93 \%$ to $99 \%$ in HCV genotype 1 monoinfected patients, including treatment-experienced patients and those with cirrhosis $(5,54,55)$. It appears that ribavirin can be omitted in genotype $1 \mathrm{~b}$, but is needed in genotype 1a (56). A New Drug Application for this regimen was filed with the FDA on April 22, 2014 (57). This regimen is currently under evaluation in the HCV-HIV coinfected patients (TURQUOISE I study). However, the presence of multiple CYP3A4-metabolized medications, including ritonavir, may limit antiretroviral treatment options in HIV coinfected patients considered for this regimen.

\section{Summary}

Collectively, these clinical trial results indicate a significant paradigm shift in the management of HCV mono- and coinfection is imminent, pending regulatory approvals and eventual addition to provincial formularies. Recent data suggest that the gap in SVR rates between HCV monoinfection and HIV-HCV coinfection has been eliminated with newer HCV antiviral regimens. The 'real-world' uptake and efficacy of these agents in vulnerable populations will be important to assess their impact on the burden of HCV disease and sequelae (1).

\section{RECOMMENDATIONS FOR THERAPY}

\section{Genotype 1 treatment-naive individuals without cirrhosis}

First line: Sofosbuvir $400 \mathrm{mg}$ daily with pegylated interferon and weight-based ribavirin for 12 weeks of therapy. This combination offers a short duration of therapy, a high SVR rate, no concerns regarding ART drug interactions and no additional side effects beyond those of pegylated interferon and ribavirin (Class 1, Level B) (see Appendix 1 for level of evidence criteria).

Alternative: Sofosbuvir $400 \mathrm{mg}$ daily with simeprevir $150 \mathrm{mg}$ daily. This regimen has not been evaluated in coinfection. However, based on the SVR rates achieved in other traditionally 'hard-to-cure' populations (ie, treatment-experienced individuals with cirrhosis), this combination can be considered preferable where available (Class 1, Level C).

Alternative: Therapy for interferon-eligible patients would consist of response-guided therapy with simeprevir $150 \mathrm{mg}$ daily with pegylated interferon and weight-based ribavirin (Class 1, Level B).

a) Genotype 1a strains must undergo Q80K polymorphism testing before use of this regimen, and an alternative DAA should be chosen if Q80K is present.

b) Response-guided therapy with treatment discontinuation at week 24 can be offered if week 4 RNA is undetectable. Responseguided therapy should not be used in individuals with underlying cirrhosis in whom a full 48-week course of pegylated interferon and ribavirin is advised.

c) Drug interactions with ART must be considered with use of simeprevir.

Alternative: Interferon-ineligible individuals can be considered for 24 weeks of sofosbuvir $400 \mathrm{mg}$ daily and weight-based ribavirin. Given the decreased SVR rates observed with this combination and limited information regarding patients with cirrhosis, deferral of therapy for future combination DAA regimens should be considered (Class 1, Level B). 
2. Genotype 1 treatment-naive individuals with cirrhosis

First line: Sofosbuvir $400 \mathrm{mg}$ daily pegylated interferon and ribavirin for 12 weeks. Patients must not have decompensated cirrhosis to receive interferon (Class 1 , Level B).

Alternative: Sofosbuvir $400 \mathrm{mg}$ daily with simeprevir $150 \mathrm{mg}$ daily for 12 weeks. This regimen has not been evaluated in coinfection. However, based on the SVR rates achieved in other traditionally 'hard-to-cure' populations (ie, treatment-experienced individuals with cirrhosis), this combination can be considered preferable where available (Class 1, Level C).

Alternative: Simeprevir $150 \mathrm{mg}$ daily for 12 weeks with pegylated interferon and ribavirin for 48 weeks (assuming genotype 1a recipient is $\mathrm{Q} 80 \mathrm{~K}$ negative) (Class 1, Level B).

\section{Genotype 1 treatment-experienced patients with previous} relapse (with or without cirrhosis)

See recommendations for genotype 1 treatment-naive individuals with or without cirrhosis as above. Retreatment with pegylated interferon, ribavirin and simeprevir is not recommended in previous relapsers, partial or null responders to other protease inhibitor (boceprevir, telaprevir)-based regimens (Class 1, Level B).

\section{Genotype 1 treatment-experienced patients - previous} nonresponders or null responders (with or without cirrhosis)

First line: Sofosbuvir $400 \mathrm{mg}$ daily with simeprevir $150 \mathrm{mg}$ daily for 12 weeks (note: based on HCV monoinfection studies) (Class 1, Level C). Or

First line: Sofosbuvir $400 \mathrm{mg}$ daily with pegylated interferon and weight-based ribavirin for 12 to 24 weeks (Class 1, Level C).

Alternative: Simeprevir $150 \mathrm{mg}$ daily for 12 weeks with 48 weeks of pegylated interferon and weight-based ribavirin (except in genotype 1a with Q80K). Response-guided therapy is recommended for noncirrhotic patients with previous relapse, whereas 48 weeks is recommended in previous partial or null responders, with or without cirrhosis (Class 1, Level B).

\section{Genotype 2 treatment-naive patient}

First line: Sofosbuvir $400 \mathrm{mg}$ daily with weight-based ribavirin for 12 weeks (Class 1, Level B).

\section{Genotype 2 treatment-experienced patient}

First line: Sofosbuvir $400 \mathrm{mg}$ daily with ribavirin for 24 weeks (Class 1, Level B).

Alternative: Sofosbuvir $400 \mathrm{mg}$ daily with pegylated interferon and ribavirin for 12 weeks (Class 1, Level C).

Recommendations for treatment-experienced coinfections are based on expert recommendation, using data from a single trial in coinfection and data from other hard-to-cure monoinfected populations.

\section{Genotype 3 treatment-naive patient}

First line: Sofosbuvir $400 \mathrm{mg}$ daily with pegylated interferon and ribavirin for 12 weeks, particularly if compensated cirrhosis is present and interferon is not contraindicated (Class 1, Level C).

Or

First line: Sofosbuvir $400 \mathrm{mg}$ daily with ribavirin for 24 weeks if interferon is contraindicated or patient considered interferon-ineligible (Class 1, Level B).

\section{Genotype 3 treatment-experienced patient}

First line: Sofosbuvir $400 \mathrm{mg}$ daily with pegylated interferon and ribavirin for 12 weeks (Class 1, Level C).

Alternative: Sofosbuvir $400 \mathrm{mg}$ daily with ribavirin for 24 weeks if interferon ineligible or intolerant (Class 1, Level B).

\section{Genotype 4 treatment-naive and experienced}

First line: Sofosbuvir $400 \mathrm{mg}$ daily with pegylated interferon and ribavirin for 12 weeks. (it should be noted that this is based on HCV monoinfection studies) (Class 1, Level C).
There are currently insufficient data in HIV-HCV coinfection with genotype 4 to 6 to comment on the efficacy of sofosbuvir-simeprevir. Likewise, there are currently insufficient data in HIV-HCV coinfection with genotype $5 / 6$ to comment on the efficacy of sofosbuvir with pegylated interferon and ribavirin.

\section{Regimens no longer recommended for first-line use}

1. Telaprevir and boceprevir are no longer recommended for first-line use given the improved safety and tolerability profiles of the new DAA agents.

2. Pegylated interferon and ribavirin as dual therapy for genotype $2 / 3$ individuals.

Circumstances may exist in which first-line regimens are not accessible to patients (eg, restricted funding). The above second-line regimens could be considered as treatment options. However, the patient must be fully aware of the diminished likelihood for cure and/or increased likelihood for adverse events compared with first-line regimens.

\section{TIMING OF INITIATION OF HCV THERAPY IN THE ERA OF DAAs}

At this time, it is unclear whether access to newer agents will be standard across the country, and/or which, if any, additional criteria may be imposed by individual provinces/payers to limit access to DAAs given the anticipated costs of these agents. Recommendations for use of newer DAA agents/combinations is based primarily on a review of the currently available data evaluating efficacy and safety in monoinfected and coinfected patients.

Access to appropriate therapy when clinically indicated has long been recommended in Canada by experts involved in the care of patients living with HCV (58), and we would continue to advocate for such an approach for coinfected patients. The authors recognize that due to potential restrictions to access and reimbursement of newer drugs/regimens for $\mathrm{HCV}$, clinicians and patients may face difficult decisions regarding therapy. In this situation, alternate options may be considered.

\section{Deferral of therapy}

Individuals with early fibrosis may be able to defer therapy compared with those with more advanced disease because they have lower risk of medium-term progression of disease. These individuals may be able to wait for future combinations and potentially improved access to interferon-free based combinations. If deferral of therapy is considered, updated staging for fibrosis progression is recommended on an annual basis if access to transient elastography is possible, or every three years if liver biopsy is to be performed. The clinician must also consider that for dual therapy with pegylated interferon plus ribavirin and triple therapy with pegylated interferon plus one DAA, SVR rates are highest at early fibrosis stages $(<\mathrm{F} 3)$ and decrease with advancing disease.

Additional considerations of patient readiness, and consideration of possible onward HCV transmission risk for individuals in a core transmitter group (injection drug users and certain populations of men who have sex with men) compared with those without high risk for transmission (eg, many 'baby boomers' ([born between approximately 1945 and 1970]) may influence a decision to consider delaying therapy.

\section{Utilization of nonpreferred regimens}

For cost/access reasons, it may be necessary to use older therapies for HCV with a higher incidence of adverse effects and lower SVR rates in some patients. In all such cases, patients should be made aware of the existence of newer improved therapies and given the option of potentially paying for them, if they so choose.

FUNDING: Support for the development of these guidelines was provided from The Canadian Institutes for Health Research Canadian HIV Trials Network and the Canadian Association for HIV Research. Unrestricted funding from Gilead Sciences, Abbvie and Roche is gratefully acknowledged. 
DISCLOSURES: $\mathrm{MH}$ has consulted and spoken for Bristol Myers Squibb, Gilead, Merck, Janssen and Vertex. MK has served as a consultant for GlaxoSmithKline and ViiV Healthcare, holds grants from Merck, has spoken for Bristol Myers Squibb, GlaxoSmithKline and ViiV Healthcare and has developed educational presentations from Gilead, GlaxoSmithKline and ViiV Healthcare. SS and CC have consulted and spoken for AbbVie, Bristol Myers Squibb, Gilead, Janssen, Merck, Vertex and Roche. AT has received unrestricted educational grants and/or spoken for Merck, Gilead and Vertex. PG has received educational grants from Merck and Vertex.

\section{APPENDIX 1}

\section{Grading system for recommendations}

\begin{tabular}{|c|c|}
\hline \multicolumn{2}{|r|}{ Classification description } \\
\hline \multicolumn{2}{|c|}{ Class of evidence } \\
\hline Class 1 & $\begin{array}{l}\text { Conditions for which there is evidence and/or general } \\
\text { agreement that a given diagnostic evaluation procedure or } \\
\text { treatment is beneficial, useful and effective }\end{array}$ \\
\hline Class 2 & $\begin{array}{l}\text { Conditions for which there is conflicting evidence and/or a } \\
\text { divergence of opinion about the usefulness/efficacy of a } \\
\text { diagnostic evaluation, procedure or treatment }\end{array}$ \\
\hline Class $2 a$ & Weight of evidence/opinion is in favour of usefulness/efficacy \\
\hline Class $2 b$ & Usefulness/efficacy is less well established by evidence/opinion \\
\hline Class 3 & $\begin{array}{l}\text { Conditions for which there is evidence and/or general } \\
\text { agreement that a diagnostic evaluation, procedure/treatment } \\
\text { is not useful/effective and in some cases may be harmful }\end{array}$ \\
\hline \multicolumn{2}{|c|}{ Grade of evidence } \\
\hline Level A & $\begin{array}{l}\text { Data derives from multiple randomized clinical trials or } \\
\text { meta-analyses }\end{array}$ \\
\hline Level B & $\begin{array}{l}\text { Data derived from a single randomized trial, or nonrandomized } \\
\text { studies }\end{array}$ \\
\hline Level C & $\begin{array}{l}\text { Only consensus opinions of experts, case studies or standard- } \\
\text { of-care }\end{array}$ \\
\hline
\end{tabular}

Adapted from references 58, 79 and 80

\section{REFERENCES}

1. Hull M, Klein M, Shafran S, et al. CIHR Canadian HIV Trials Network Coinfection and Concurrent Diseases Core: Canadian guidelines for management and treatment of HIV/hepatitis C coinfection in adults. Can J Infect Dis Med Microbiol 2013;24:217-38.

2. Recommendations for testing, managing, and treating hepatitis $\mathrm{C}$. American Association for the Study of Liver Diseases and the Infectious Diseases Society of America, 2014. <www.hcvguidelines. org $>$ (Accessed April 24, 2014).

3. Lawitz E, Poordad FF, Pang PS, et al. Sofosbuvir and ledipasvir fixed-dose combination with and without ribavirin in treatment-naive and previously treated patients with genotype 1 hepatitis $\mathrm{C}$ virus infection (LONESTAR): An open-label, randomised, phase 2 trial. Lancet 2014;383:515-23.

4. Afdhal N, Reddy KR, Nelson DR, et al. Ledipasvir and sofosbuvir for previously treated HCV genotype 1 infection. N Engl J Med 2014;370:1483-93.

5. Feld JJ, Kowdley KV, Coakley E, et al. Treatment of HCV with ABT-450/r-ombitasvir and dasabuvir with ribavirin. N Engl J Med 2014;370:1594-603.

6. Poordad F, McCone J Jr, Bacon BR, et al. Boceprevir for untreated chronic HCV genotype 1 infection. N Engl J Med 2011;364:1195-206.

7. Bacon BR, Gordon SC, Lawitz E, et al. Boceprevir for previously treated chronic HCV genotype 1 infection. N Engl J Med 2011;364:1207-17.

8. Jacobson IM, McHutchison JG, Dusheiko G, et al. Telaprevir for previously untreated chronic hepatitis $C$ virus infection. N Engl J Med 2011;364:2405-16.

9. Zeuzem S, Andreone P, Pol S, et al. Telaprevir for retreatment of HCV infection. N Engl J Med 2011;364:2417-28.

10. Sulkowski MS, Sherman KE, Dieterich DT, et al. Combination therapy with telaprevir for chronic hepatitis $\mathrm{C}$ virus genotype 1 infection in patients with HIV: A randomized trial. Ann Intern Med 2013;159:86-96.
11. Sulkowski M, Pol S, Mallolas J, et al. Boceprevir versus placebo with pegylated interferon alfa-2b and ribavirin for treatment of hepatitis $C$ virus genotype 1 in patients with HIV: A randomised, double-blind, controlled phase 2 trial. Lancet Infect Dis 2013;13:597-605.

12. Torriani FJ, Rodriguez-Torres M, Rockstroh JK, et al. Peginterferon alfa-2a plus ribavirin for chronic hepatitis $\mathrm{C}$ virus infection in HIVinfected patients. N Engl J Med 2004;351:438-50.

13. Buti M, Agarwal K, Horsmans Y, et al. Telaprevir twice daily is noninferior to telaprevir every 8 hours for patients with chronic hepatitis C. Gastroenterology 2014;146:744-53, e3.

14. Hare CD, Sherman K, Talal AH, et al. Simplified dosing and responseguided therapy using telaprevir combination treatment for genotype 1 HCV treatment-naïve or -experienced HIV co-infected patients: UNITE interim analysis. (Abstract 64). Proceedings and Abstracts of HEP DART 2013. Big Island, December 8 to 12, 2013.

15. Montes M, Nelson M, Girard et al. Telaprevir combination therapy in treatment-naive and experienced patients co-infected with HCV and HIV. (Abstract 38). Program and abstracts of the 64th Annual Meeting of the American Association for the Study of Liver Diseases. Washington, DC, November 1 to 5, 2013.

16. Cotte L, Braun J, Lascoux-Combe C, et al. High early virologic response with telaprevir-pegylated interferon-ribavirin in treatment-experienced HCV genotype 1/HIV co-infected patients: ANRS HC26 TelapreVIH Study. (Abstract 36). 20th Conference on Retroviruses and Opportunistic Infections. Atlanta, March 3 to 6, 2013.

17. Cotte L, Braun J, Lascoux-Combe C, et al. Telaprevir for HIV/hepatitis C virus-coinfected patients failing treatment with pegylated interferon/ribavirin (ANRS HC26 TelapreVIH): An open-label, single-arm, phase 2 trial. Clin Infect Dis August 18, 2014 [Epub ahead of print].

18. Poizette-Martin I, Bellissant E, Piroth L, et al. W48 response rate of boceprevir-pegIFN-RBV in treatment-experienced HIV coinfected patients with HCV genotype 1: ANRS-HC27 BocepreVIH Study. (Abstract 1105). Program and Abstracts of the 64th American Association for the Study of Liver Diseases. Washington, DC, November 7 to $11,2013$.

19. Poizette-Martin I, Bellissant E, Colson P, et al, eds. Boceprevir for previously treated HCV-HIV coinfected patients: The ANRSHC27 BocepreVIH trial. (Abstract 659LB). Abstracts and Proceedings of the 21st Conference on Retroviruses and Opportunistic Infections (CROI). Boston, March 3 to 6, 2014.

20. Galexos (simeprevir) Product Monograph. Janssen Inc. Toronto, 2013.

21. Ouwerkerk-Mahadevan S, Simion S, Mortier E, et al. No clinically significant interaction between the investigational $\mathrm{HCV}$ protease inhibitor simeprevir (TMC435) and the immunosuppressive agents cyclosporine and tacrolimus. (Abstract 80 ). Abstracts and Proceedings of the 63rd Annual Meeting of the American Association for the Study of Liver Diseases (AASLD). Boston, November 9 to $13,2012$.

22. Fried MW, Buti M, Dore GJ, et al. Once-daily simeprevir (TMC435) with pegylated interferon and ribavirin in treatmentnaive genotype 1 hepatitis C: The randomized PILLAR study. Hepatology 2013;58:1918-29.

23. Zeuzem S, Berg T, Gane E, et al. Simeprevir increases rate of sustained virologic response among treatment-experienced patients with HCV genotype-1 infection: A phase IIb trial. Gastroenterology 2014;146:430-41 e6.

24. Jacobson IM, Dore GJ, Foster GR, et al. Simeprevir (TMC435) with peginterferon/ribavirin for chronic HCV genotype-1 infection in treatment-naive patients: Results from QUEST-1, a phase III trial. (Abstract 1425). Program and abstracts of the 48th Annual Meeting of the European Association for the Study of the Liver. Amsterdam, April 24 to 28, 2013.

25. Manns M, Marcellin P, Poordad F, et al. Simeprevir (TMC435) with peginterferon/ribavirin for treatment of chronic HCV genotype-1 infection in treatment-naive patients: Results from QUEST-2, a phase III trial. (Abstract 1413). Program and abstracts of the 48th Annual Meeting of the European Association for the Study of the Liver. Amsterdam, April 24 to 28, 2013.

26. Forns X, Lawitz E, Zeuzem S, et al. Simeprevir with peginterferon and ribavirin leads to high rates of SVR in patients with HCV genotype 1 who relapsed after previous therapy: A phase 3 trial. Gastroenterology 2014;146:1669-79 e3. 
27. Reddy KR, Zeuzem S, Zoulim F, et al. A phase III randomised, double-blind study to evaluate the efficacy, safety and tolerability of simeprevir vs telaprevir in combination with pegylated interferon and ribavirin in chronic hepatitis $\mathrm{C}$ virus genotype 1 treatmentexperienced patients: The ATTAIN study. Proceedings and Abstracts of the Asian Pacific Association of the Study of the Liver. Brisbane, March 12 to 14, 2014.

28. Andonov A, Kadkhoda K, Osiowy C, Kaita K. Pretreatment resistance to hepatitis $\mathrm{C}$ virus protease inhibitors boceprevir/ telaprevir in hepatitis $\mathrm{C}$ virus subgenotype 1a-infected patients from Manitoba. Can J Gastroenterol 2013;27:414-6.

29. Vicenti I, Rosi A, Saladini F, et al. Naturally occurring hepatitis C virus (HCV) NS3/4A protease inhibitor resistance-related mutations in HCV genotype 1-infected subjects in Italy. J Antimicrob Chemother 2012;67:984-7.

30. Dieterich D, Rockstroh J, Orkin C, et al. Simeprevir (TMC435) with peginterferon/ribavirin in patients coinfected with $\mathrm{HCV}$ genotype-1 and HIV-1: A phase III study. Clin Infec Dis 2014;59:1579-87.

31. SOVALDI Product Monograph. Gilead Sciences Canada, Inc. Mississauga, 2013

32. Lawitz E, Mangia A, Wyles D, et al. Sofosbuvir for previously untreated chronic hepatitis C infection. N Engl J Med 2013;368:1878-87.

33. Osinusi A, Meissner EG, Lee YJ, et al. Sofosbuvir and ribavirin for hepatitis $C$ genotype 1 in patients with unfavorable treatment characteristics: A randomized clinical trial. JAMA 2013;310:804-11.

34. Gane EJ, Stedman CA, Hyland RH, et al. Nucleotide polymerase inhibitor sofosbuvir plus ribavirin for hepatitis C. N Engl J Med 2013;368:34-44.

35. Lalezari J, Nelson D, Hyland RH, et al. Once daily sofosbuvir plus ribavirin for 12 and 24 weeks in treatment-naive patients with HCV infection: The QUANTUM study. (Abstract 845). Program and abstracts of the 48th Annual Meeting of the European Association for the Study of the Liver. Amsterdam, April 24 to 28, 2013.

36. Muir A, Nelson D, Gordon S, et al. Modeling predicts clinically meaningful SVR rates in genotype 1 treatment-experienced patients based on results in genotype 1 treatment-naive patients treated with sofosbuvir+ peginterferon+ ribavirin for 12 weeks. (Abstract P1220). Abstracts and Proceedings of the 49th European Association for the Study of the Liver meeting. London, April 9 to 13, 2014.

37. Jacobson IM, Gordon SC, Kowdley KV, et al. Sofosbuvir for hepatitis C genotype 2 or 3 in patients without treatment options. N Engl J Med 2013;368:1867-77.

38. Zeuzem S, Dushelko GM, Salupere R, et al. Sofosbuvir + ribavirin for 12 or 24 weeks for patients with HCV genotype 2 or 3 : The VALENCE trial. (Abstract 1085) Program and abstracts of the 64th Annual Meeting of the American Association for the Study of Liver Diseases; 2013 November 1-5; Washington, DC.

39. Zeuzem S, Dusheiko GM, Salupere R, et al. Sofosbuvir and ribavirin in HCV genotypes 2 and 3. N Engl J Med 2014;370:1993-2001.

40. Lawitz E, Poordad F, Brainard D, et al. Sofosbuvir in combination with pegIFN and ribavirin for 12 weeks provides high SVR rates in HCV-infected genotype 2 or 3 treatment experienced patients with and without compensated cirrhosis: Results from the LONESTAR-2 study. (Abstract LB4). Program and abstracts of the 64th Annual Meeting of the American Association for the Study of Liver Diseases. Washington, DC, November 1 to 5, 2013.

41. Rodriguez-Torres M, Rodriguez-Orengo J, Gaggar A, et al. Sofosbuvir and peginterferon alfa-2a/ribavirin for treatment-naïve genotype 1-4 HCV-infected patients who are coinfected with HIV. (Abstract 714). Abstracts and Proceedings of IDWeek. San Francisco, October 2 to 6, 2013.

42. Sulkowski M, Naggie S, Lalezari J, et al. Sofosbuvir and ribavirin for hepatitis $C$ in patients with HIV coinfection. JAMA 2014;312:353-61.

43. Lok AS, Gardiner DF, Lawitz E, et al. Preliminary study of two antiviral agents for hepatitis C genotype 1. N Engl J Med 2012;366:216-24.

44. Poordad F, Lawitz E, Kowdley KV, et al. Exploratory study of oral combination antiviral therapy for hepatitis C. N Engl J Med 2013;368:45-53.

45. Zeuzem S, Soriano V, Asselah T, et al. Faldaprevir and deleobuvir for HCV genotype 1 infection. N Engl J Med 2013;369:630-9.

46. Jacobson IM, Ghalib R, Rodriguez-Torres M, et al, eds. SVR results of a once-daily regimen of simeprevir (TMC435) plus sofosbuvir (GS7977) with or without ribavirin in cirrhotic and non-cirrhotic HCV genotype 1 treatment-naive and prior null responder patients: The COSMOS study. (Abstract LB3). Program and abstracts of the 64th Annual Meeting of the American Association for the Study of Liver Diseases. Washington, DC, November 1 to 5, 2013.

47. Sulkowski M, Gardiner DF, Rodriguez-Torres M, et al. Sustained virologic response with daclatasvir plus sofosbuvir \pm ribavirin (RBV) in chronic HCV genotype (GT) 1-infected patients who previously failed telaprevir (TVR) or boceprevir (BOC). (Abstract 1417). Program and abstracts of the 48th Annual Meeting of the European Association for the Study of the Liver. Amsterdam, April 24 to 28, 2013.

48. Sulkowski M, Jacobson IM, Ghalib R, et al. Once-daily simeprevir (TMC435) plus sofosbuvir (GS-7977) with or without ribavirin in HCV genotype 1 prior null responders with Metavir F0-2: COSMOS study subgroup analysis. (Abstract 07). Abstracts and Proceedings of the 49th Annual Meeting of the European Association for the Study of the Liver. London, April 9 to 13, 2014.

49. Lawitz E, Ghalib R, Rodriguez-Torres M, et al. Simeprevir plus sofosbuvir with/without ribavirin in HCVgenotype 1 prior nullresponder/treatment-naive patients (COSMOS study): Primary endpoint (SVR12) results in patients with Metavir F3-4 (Cohort 2). (Abstract O165). Abstracts and Proceedings of the 49th Annual Meeting of the European Association for the Study of the Liver. London, April 9 to 13, 2014.

50. Janssen Initiates Phase 3 OPTIMIST Trials of Once-Daily Simeprevir in Combination with Once-Daily Sofosbuvir for the Treatment of Genotype 1 Chronic Hepatitis C [PDF]: Janssen Pharmaceutical Companies. Updated April 2, 2014. <www.janssenrnd.com/sites/ default/files/pdf/OPTIMIST-Press_Release_FINAL_4\%201_14_v3_ clean.pdf $\#$ zoom $=125>$ (Accessed May 30, 2014).

51. Sulkowski MS, Gardiner DF, Rodriguez-Torres M, et al. Daclatasvir plus sofosbuvir for previously treated or untreated chronic HCV infection. N Engl J Med 2014;370:211-21.

52. Kowdley KV, Gordon SC, Reddy KR, et al. Ledipasvir and sofosbuvir for 8 or 12 Weeks for chronic HCV without cirrhosis. N Engl J Med 2014:1879-88.

53. Gilead Files for U.S. Approval of ledipasvir/sofosbuvir fixed-dose combination tablet for genotype 1 hepatitis C. [Web Page]: Gilead Sciences, Inc. Updated February 10, 2014. <www.gilead.com/news/ press-releases/2014/2/gilead-files-for-us-approval-of-

ledipasvirsofosbuvir-fixeddose-combination-tablet-for-genotype-1hepatitis-c> (Accessed May 30, 2014).

54. Zeuzem S, Jacobson IM, Baykal T, et al. Retreatment of HCV with ABT-450/r-ombitasvir and dasabuvir with ribavirin. N Engl J Med 2014;370:1604-14.

55. Poordad F, Hezode C, Trinh R, et al. ABT-450/r-ombitasvir and dasabuvir with ribavirin for hepatitis $\mathrm{C}$ with cirrhosis. N Engl J Med 2014;370:1973-82.

56. Ferenci P, Bernstein D, Lalezari J, et al. ABT-450/r-ombitasvir and dasabuvir with or without ribavirin for HCV. N Engl J Med 2014370:1983-92.

57. AbbVie Submits New Drug Application to U.S. FDA for its Investigational, All-Oral, Interferon-Free Therapy for the Treatment of Hepatitis C. AbbVie. Updated April 22, 2014. $<$ http://abbvie.mediaroom.com/2014-04-22-AbbVie-Submits-NewDrug-Application-to-U-S-FDA-for-its-Investigational-All-OralInterferon-Free-Therapy-for-the-Treatment-of-Hepatitis-C> (Accessed May 30, 2014).

58. Myers RP, Ramji A, Bilodeau M, Wong S, Feld JJ. An update on the management of hepatitis $\mathrm{C}$ : Consensus guidelines from the Canadian Association for the Study of the Liver. Can J Gastroenterol 2012;26:359-75.

59. Johnson M, Borland J, Chen S, et al. The effect of boceprevir and telaprevir on dolutegravir pharmacokinetics, in healthy adult subjects. (Abstract O-16). Program and Abstracts of the 14th International Workshop on Clinical Pharmacology of HIV Therapy; Amsterdam, April 22 to 24, 2013.

60. ViiV Healthcare ULC. Tivicay (dolutegravir) Prescribing Information. North Carolina: Research Triangle Park, 2013.

61. Custodio J, Guo S, Lawson EB, et al. Lack of clinically relevant drug interactions between elvitegravir/cobicistat/emtricitabine/ tenofovir disoproxil fumarate and telaprevir. (Abstract A-1576). 53rd Interscience Conference on Antimicrobial Agents and Chemotherapy (ICAAC). Denver, September 10 to 13, 2013. 
62. Ouwerkerk-Mahadevan S, Simion A, Peeters M, Beumont-Mauviel M. Summary of pharmacokinetic drug-drug interactions for simeprevir (TMC435), a hepatitis $\mathrm{C}$ virus NS3/4A protease inhibitor. (Abstract PE 10/7). Program and Abstracts of the 14th European AIDS Conference (EACS). Brussels, October 16 to 19, 2013.

63. de Kanter C, Blonk M, Colbers A, Schouwenberg B, Burger D. Lack of a clinically significant drug-drug interaction in healthy volunteers between the hepatitis $\mathrm{C}$ virus protease inhibitor boceprevir and the HIV integrase inhibitor raltegravir. Clin Infec Dis 2013;56:300-6.

64. Van Heeswijk R, Garg V, Boogaerts G, et al. The pharmacokinetic interaction between telaprevir and raltegravir in healthy volunteers. (Abstract A1-1738a). Abstracts and Proceedings of the 51st Interscience Conference on Antimicrobial Agents and Chemotherapy. Chicago, September 17 to 20, 2011.

65. Ouwerkerk-Mahadevan S, Sekar V, Peeters M, Beumont-Mauviel M. The pharmokinetic interactions of HCV protease inhibitor TMC435 with rilpivirine, tenofovir, efavirenz or raltegravir in healthy volunteers. (Abstract 49). Program and Abstracts of the 19th Conference on Retroviruses and Opportunistic Infections. Seattle, March 5 to 8, 2012.

66. Kirby B, Mathias A, Rossi S, Moyer C, Shen G, Kearney BP. No clinically significant pharmacokinetic interactions between sofosbuvir (GS-7977) and HIV antiretrovirals Atripla, rilpivirine, darunavir/ritonavir, or raltegravir in healthy volunteers. (Abstract 1877). Program and Abstracts of the 63rd Annual Meeting of the American Association for the Study of Liver Diseases (AASLD). Boston, November 9 to 13, 2012.

67. Kasserra C, Hughes E, Treitel M, Gupta S, O’Mara E. Clinical pharmacology of boceprevir: metabolism, excretion, and drug-drug interactions. (Abstract 118). Program and Abstracts of the 18th Conference on Retroviruses and Opportunistic Infections. Boston, February 27 to March 2, 2011.

68. Merck Canada Inc. Victrelis (boceprevir) Product Monograph. Kirkland, QC2013.

69. Garg V, Chandorkar G, Yang Y, et al. The effect of CYP3A inhibitors and inducers on the pharmacokinetics of telaprevir [abstract PK_13]. Program and Abstracts of the 6th International Workshop on Clinical Pharmacology of Hepatitis Therapy. Cambridge, June 22 to 23, 2011.

70. Van Heeswijk R, Vandevoorde A, Boogaerts G, et al. Pharmacokinetic interactions between ARV agents and the investigational HCV protease inhibitor TVR in healthy volunteers. (Abstract 119). Abstracts and Proceedings of the18th Conference on Retroviruses and Opportunistic Infections. Boston,

February 27 to March 2, 2011.

71. Hammond K, Wolfe P, Burton J, et al. Pharmacokinetic interaction between boceprevir and etravirine in HIV/HCV seronegative volunteers. J Acq Immune Def Syndr 2013;62:67-73.

72. Kakuda TN, Leopold L, Nijs S, et al. Pharmacokinetic interaction between etravirine or rilpivirine and telaprevir:

A randomised, two-way crossover trial. (Abstract O-18). Program and Abstracts of the 13th International Workshop on Clinical Pharmacology of HIV Therapy. Barcelona, April 16 to 18, 2012.

73. Rhee E, Feng H-P, Xuan F, et al. Absence of a significant pharmacokinetic interaction between the hepatitis $\mathrm{C}$ virus protease inhibitor boceprevir and HIV-1 NNRTI rilpivirine. (Abstract 537). Abstracts and Proceedings of the 20th Conference on Retroviruses and Opportunistic Infections (CROI). Atlanta, March 3 to 6, 2013.

74. Hulskotte EGJ, Feng H-P, Xuan F, et al. Pharmacokinetic interactions between the hepatitis $C$ virus protease inhibitor boceprevir and ritonavir-boosted HIV-1 protease inhibitors atazanavir, darunavir, and lopinavir. Clin Infec Dis 2013;56:718-26.

75. Vertex Pharmaceuticals Inc. Incivek (telaprevir) Product Monograph. Laval, 2013.

76. AbbVie Corporation. Kaletra (lopinavir/ritonavir) Prescribing Information. Saint Laurent, Canada 2012.

77. Vourvahis M, Plotka A, Kantaridis C, Fang A, Heera J. The effects of boceprevir and telaprevir on the pharmacokinetics of maraviroc: An open-label, fixed-sequence study in healthy volunteers. J Acquir Immune Defic Syndr 2014;65:564-70.

78. Martel D, Sheehan N, Tremblay C, et al. Pharmacokinetic interaction of the directly acting antiviral agent boceprevir and maraviroc in healthy volunteers. (Abstract P-04). Program and Abstracts of the 14th International Workshop on Clinical Pharmacology of HIV Therapy. Amsterdam, April 22 to 24, 2013.

79. Shiffman RN, Shekelle P, Overhage JM, Slutsky J, Grimshaw J, Deshpande AM. Standardized reporting of clinical practice guidelines: A proposal from the Conference on Guideline Standardization. Ann Intern Med 2003;139:493-8.

80. Ghany MG, Nelson DR, Strader DB, Thomas DL, Seeff LB. An update on treatment of genotype 1 chronic hepatitis $C$ virus infection: 2011 practice guideline by the American Association for the Study of Liver Diseases. Hepatology 2011;54:1433-44. 


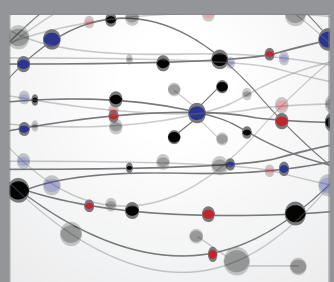

The Scientific World Journal
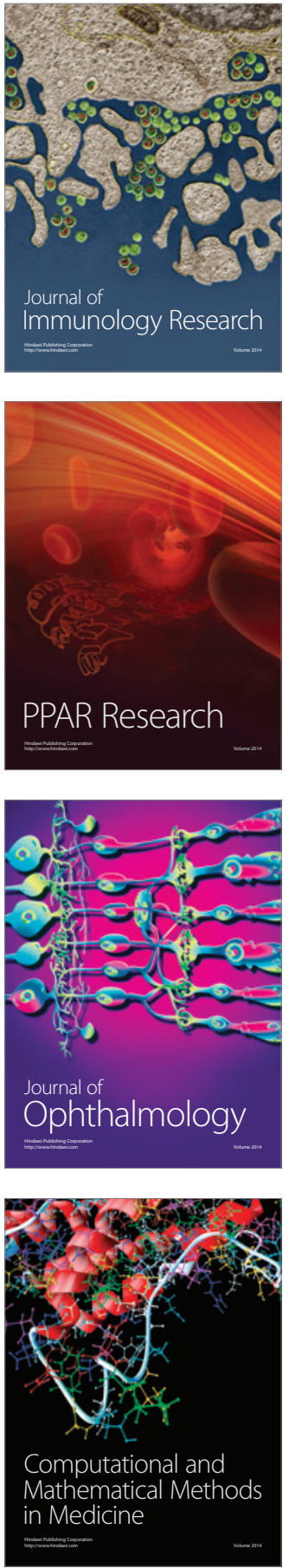

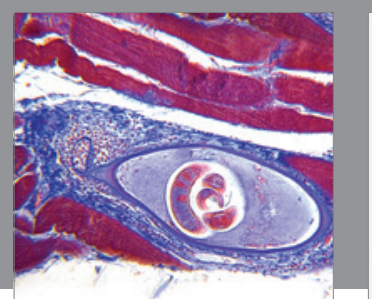

Gastroenterology Research and Practice

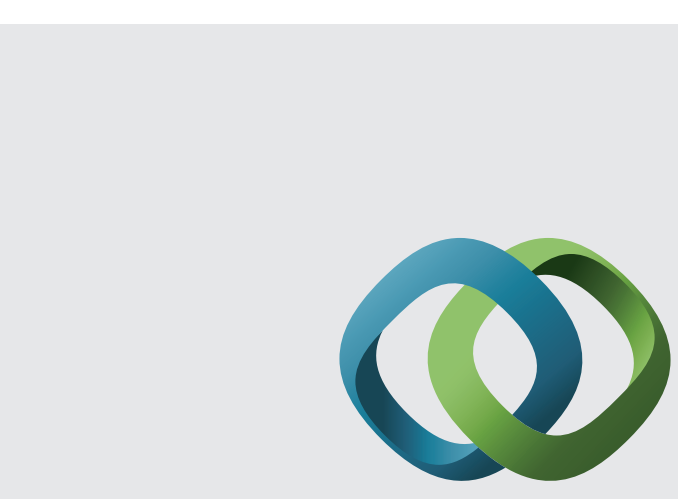

\section{Hindawi}

Submit your manuscripts at

http://www.hindawi.com
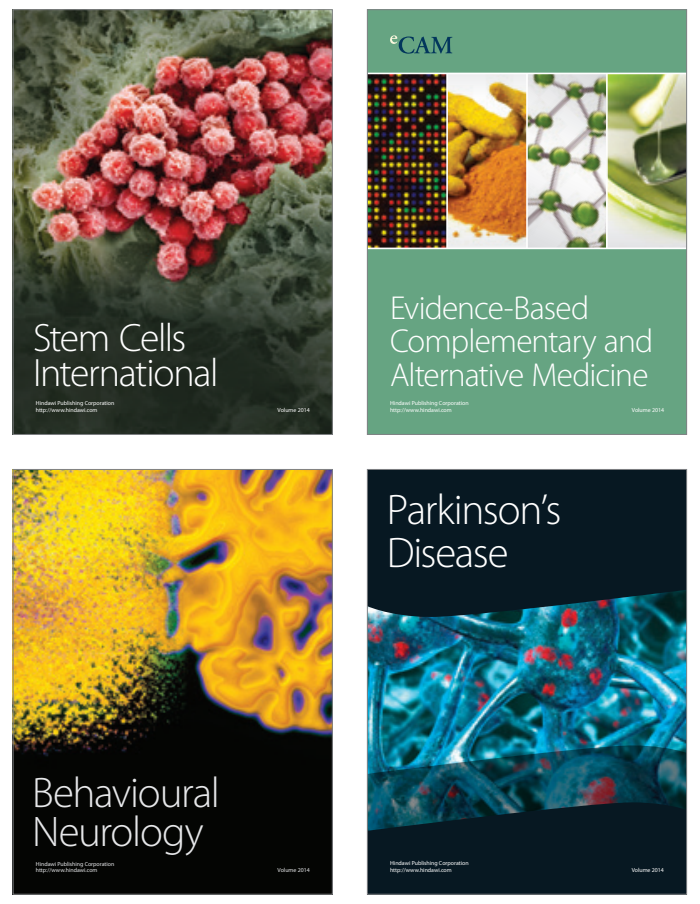
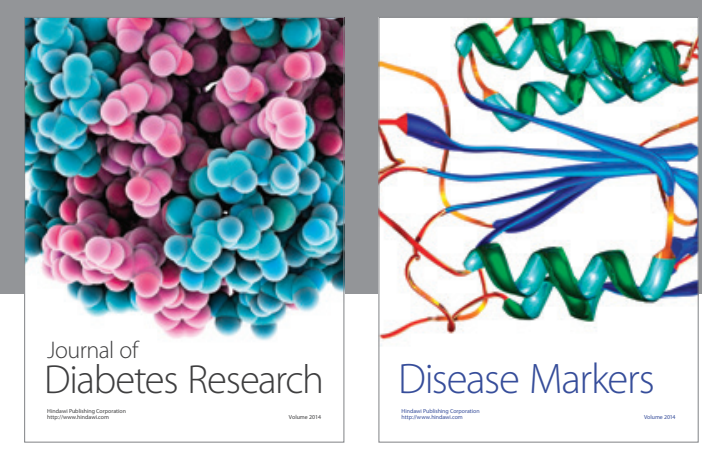

Disease Markers
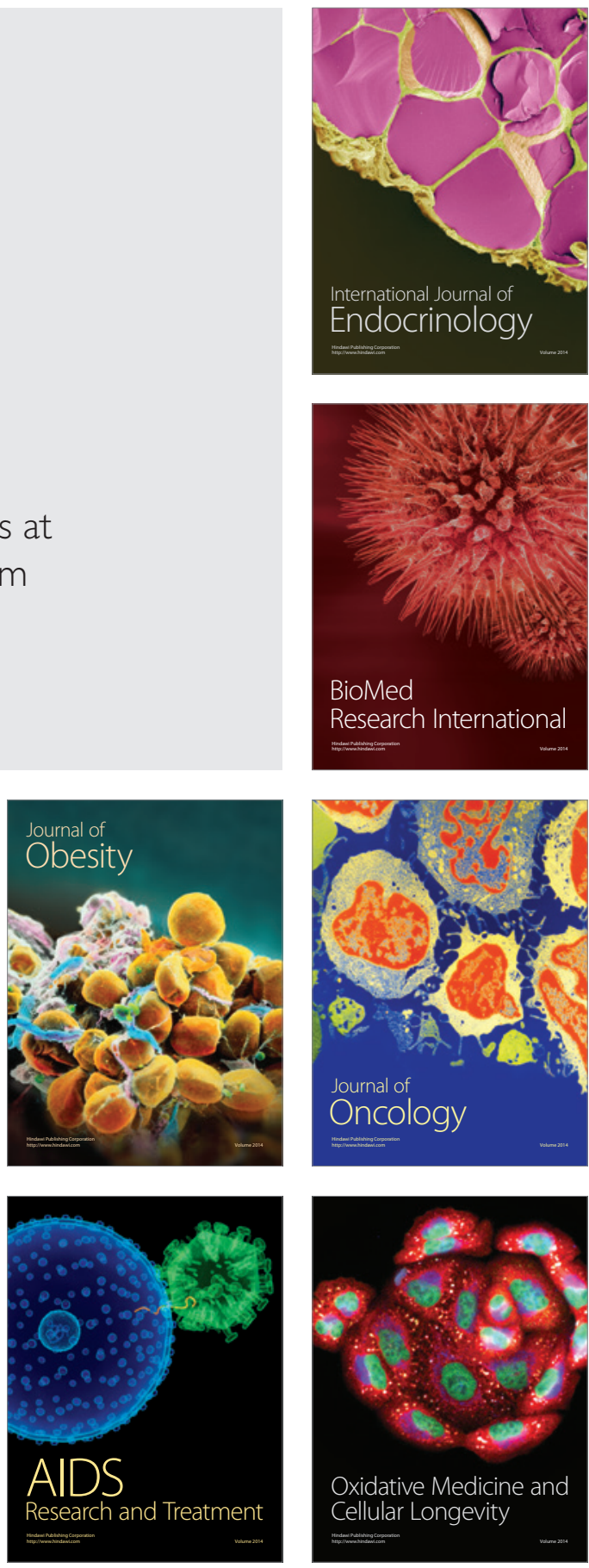